\title{
A PRODUÇÃO DA "CIDADE OLÍMPICA" E O CONTEXTO DO EMPREENDEDORISMO URBANO NO RIO DE JANEIRO
}

\author{
Fabio Silveira Molina
}

R E S U M O : O tema deste trabalho se assenta no papel dos megaeventos esportivos internacionais no processo de produção do espaço urbano do Rio de Janeiro, marcado pela produção da "Cidade Olimpica". Iniciada na ocasiāo dos Jogos Pan-Americanos de 2007 e atualmente em curso para sediar os Jogos Olimpicos de 2016, essa produção utiliza-se de padröes de urbanização importados e se aplica, assim, o "modelo Barcelona" de urbanismo, sob o paradigma do empreendedorismo urbano e do planejamento estratégico. Nesse sentido, os megaeventos são utilizados enquanto estratégias urbanas e mostram-se relevantes na (re)estruturação da cidade do Rio de Janeiro.

P A L A V R A S - C H A V E : megaeventos esportivos internacionais; empreendedorismo urbano; planejamento estratégico; geografia urbana; produção do espaço urbano; estrutura urbana.

\section{INTRODUÇÃO}

O Rio de Janeiro em breve se tornará a "Cidade Olímpica”, configurando-se como a primeira na América do Sul a conquistar esse título almejado por tantas outras no âmbito da competitividade internacional entre cidades que, além de tornadas produtos, são governadas atualmente aos moldes de uma empresa. Esse acontecimento adquire grandes proporções na cidade (e no país, que também sediará, pela segunda vez, uma Copa do Mundo), pois se trata do megaevento internacional de maior relevância (e repercussōes espaciais) na atualidade para uma cidade: sediá-lo significa estar em evidência, em escala planetária.

Ao mesmo tempo, significa a oportunidade de captação de investimentos, negócios, turistas, além da obtenção de prestígio e reconhecimento internacional. Durante os Jogos Olímpicos de 2016, os "olhos do mundo" estarão atentos à "Cidade Maravilhosa" que busca inserir-se, de forma mais competitiva, no mapa (ou mercado) mundial de cidades. Algo parecido ocorreu no Rio, em um passado recente e de forma mais tímida, ao sediar os Jogos Pan-Americanos de 2007, em parte exitoso em seus objetivos, dentre eles o de "preparar terreno" para a candidatura aos Jogos Olímpicos, configurando-se como um marco inicial da produção da "Cidade Olímpica". Dessa forma, o momento atual dessa produção soma-se às transformaçôes urbanas antes realizadas para os Jogos Pan-Americanos de 2007.

Os megaeventos esportivos internacionais no Rio de Janeiro são tomados pelo poder público municipal (em parceria com o setor privado) como ferramentas ou 
pretextos para as diversas intervençôes urbanas levadas a cabo na cidade, no momento atual da produção espacial da cidade movida, em grande parte, pela futura realização dos Jogos Olímpicos de 2016. Nesse contexto, as atençôes têm-se dirigido a fragmentos da cidade atrativos ao capital, promovendo-se a criação de novos objetos e açóes inseridos na lógica intrínseca aos megaeventos, à valorização do espaço e ao seu consumo, buscando ainda atuar na imagem da cidade no intuito de inseri-la no mapa (ou mercado) mundial de cidades.

Tendo em vista o lugar dos megaeventos esportivos internacionais no processo de urbanização da cidade do Rio de Janeiro no início do século XXI, buscamos apreender neste trabalho de que forma os mesmos atuam na produção de seu espaço urbano e na (re)estruturação da cidade a partir da lógica de suas localizaçóes intraurbanas, das inovaçôes territoriais materializadas em função dos mesmos, da produção de novas formas, da refuncionalização de formas pretéritas, dos novos usos de parcelas do espaço e da ressignificação de determinadas áreas na cidade.

\section{MEGAEVENTOS E PRODUÇÃO DO ESPAÇO URBANO}

Os megaeventos são verdadeiros espetáculos cujas expressóes concretas são materializadas no espaço interno das cidades e se configuram, notadamente, como estratégias urbanas adotadas pelo poder público aliado à iniciativa privada. Esse fenômeno é mais aparente nas últimas décadas, especialmente a partir da década de 1980 e no contexto do empreendedorismo urbano e gestão das cidades sob a lógica empresarial; dessa forma, esta assertiva nos conduziu a uma abordagem geográfica norteada pela relação entre os megaeventos e a produção do espaço urbano no contexto nacional, constatando-se que a realização de megaeventos pode envolver tanto a incorporação de novas áreas à cidade como a refuncionalizaçáo seletiva de áreas existentes no espaço intraurbano, através de intervençóes urbanas de grande impacto na reestruturação da cidade, acentuando processos de fragmentaçáo e criando ou reforçando centralidades.

Megaeventos trazem consigo uma profusão de megaprojetos urbanos promovidos pelo poder público em parceria com o setor privado (ou mesmo essencialmente privados), envolvendo a construçáo de pontes, túneis, canais, aprimoramento do sistema de transportes público, monumentos e edifícios com certo prestígio (e valor simbólico, arquitetônico). No caso de um megaevento esportivo, os megaprojetos envolvem ainda a construção de infraestruturas esportivas e estádios.

A estreita relação entre megaeventos e construção de edificado é amplamente discutida por Indovina (1999). O autor assevera que um megaevento só pode ser considerado como tal se produzir transformaçóes urbanas (construçóes) no local onde se realiza, ou seja, o megaevento é considerado, também, como uma ocasiáo para a realização de obras relevantes na cidade, de forma a "enriquecê-la" ou mesmo tornar esses novos equipamentos urbanos úteis à coletividade, algo que nem sempre corresponde à realidade.

Um megaevento refere-se, basicamente, à larga escala de abrangência (expressividade internacional), duração e visibilidade (proporcionada, entre outros, pela cobertura midiática), à dimensão simbólica capaz de proporcionar a atração de pessoas e capitais (investimentos) e, sobretudo, à sua dimensão espacial, ou seja, ao seu poder 
de induzir, direta ou indiretamente, consideráveis transformaçóes espaciais nas cidades nas quais os mesmos ocorrem, manifestadas materialmente através da construção de edificado (em geral), de obras de infraestrutura, da disponibilização (ou conquista) de novos terrenos (dotando-os de infraestrutura e edificações diversas) e, por vezes, da ressignificação de áreas inteiras para a realização do megaevento e, ao mesmo tempo, prevendo sua utilização futura, dado o seu caráter essencialmente efêmero.

Diante do exposto, não há como desconsiderar o papel dos megaeventos no processo de urbanização e produção do espaço urbano em seus diversos momentos e contextos $^{1}$. Expressão material desse processo, a cidade, em toda a sua complexidade, é estruturada de acordo com os diferentes momentos de sua realização. O processo de urbanização refere-se a um complexo e dinâmico processo de transformação (de forma e conteúdo): a cada momento da história surgem mudanças estruturais e organizacionais e, nesse sentido, a urbanização (e suas características particulares num determinado momento) é redefinida.

A industrialização, a intensificação das trocas e a multiplicação de intermediários financeiros, bem como a consolidação do setor de serviços (terciarização da economia) e as formas recentes de produção flexíveis no contexto da globalizaçấo, intensificaram a urbanização e são elementos-chave na compreensão desse processo que se ressignifica ao longo do tempo. As ressignificaçôes e os novos rumos no processo de urbanização repercutem diretamente na estrutura urbana, compreendida como o arranjo interno dos diferentes usos do solo num determinado momento (SPOSITO, 1991).

A estrutura urbana é constantemente redefinida em função de diversos fatores, dentre eles a expansão territorial e os novos usos do solo que, no curso da urbanização e produção espacial, e sob a ação de determinados agentes (responsáveis também por desestruturaçôes), implicam na reestruturação da cidade atrelada, basicamente, aos processos de fragmentação e centralização.

A fragmentação espacial resulta de açóes homogeneizantes e que, de forma contraditória, induzem a um processo que divide o espaço em parcelas menores. Essas parcelas são produzidas e vendidas enquanto solo urbano e, portanto, tornadas mercadoria, acabando por restringir o uso (CARLOS, 2002). Produto da produção capitalista do espaço e da imposição do homogêneo, o processo de fragmentação é concomitante ao de valorizaçáo espacial e se revela na paisagem urbana através de uma morfologia diversificada e marcada pela heterogeneidade espacial inerente aos diferentes usos do solo urbano, denotando uma contradição. Nesse sentido, a cidade se apresenta de forma fragmentada, apesar de constituir uma unidade (a totalidade da cidade, manifestada num determinado momento da estrutura urbana).

O processo de urbanizaçáo no contexto recente, marcado pela globalizaçáo (ou período técnico-científico-informacional), acentua os processos que induzem à fragmentação espacial. Nesse contexto, a fragmentação se revela também na exacerbação da reprodução do idêntico e do repetitivo e na tendência à multiplicação de áreas de centralidade em oposição à cidade marcada, no passado, por um centro único e periferia esparsa.

A centralidade é um atributo (ou qualificativo) de parcelas do espaço cuja expressão maior se traduz, basicamente, na capacidade de atrair fluxos de diversas naturezas e concentrar objetos, pessoas e açôes. Uma área dotada de centralidade representa o lugar dotado das melhores condiçôes de infraestrutura e equipamentos urbanos, foco de atração de investimentos, pessoas (consumidores), comércio, serviços, entre outros.
1 Um megaevento, todavia, somente pode ser melhor compreendido a partir do contexto (social, político, econômico, cultural) de sua realização, assim como do lugar onde se instala e de suas especificidades. 
2 Ou seja, à consolidação de novas áreas de centralidade no espaço interno das cidades.
$\mathrm{O}$ movimento relativamente recente que conduz à multicentralidade ${ }^{2}$ revela o aprofundamento do processo de fragmentação espacial, na medida em que a constituição (ou redefinição/reforço) de áreas de centralidade pode implicar tanto na incorporação de novas áreas como na ressignificação de lugares da cidade, redefinindo usos do solo urbano nessas áreas valorizadas. A centralidade constitui-se, assim, como expressão do processo de fragmentação espacial e, nesse contexto, a análise de como os megaeventos se inscrevem no espaço intraurbano pode ser reveladora do seu papel na (re)estruturação das cidades, tendo em vista o pressuposto de que, a partir da segunda metade do século XX, especialmente na década de 1990, os megaeventos esportivos internacionais configuraram-se como importantes elementos indutores de profundas transformaçóes urbanas nas cidades que os sediam. Estas, em busca de visibilidade internacional, e no contexto da globalização e da competitividade entre cidades, participam de acirradas disputas para sediar megaeventos esportivos internacionais, especialmente os Jogos Olímpicos, utilizando-se desse megaevento como estratégia para a realização de intervençôes urbanas voltadas, sobretudo, às oportunidades de lucratividade e de melhorias na imagem da cidade.

Megaeventos como os Jogos Olímpicos e mesmo os Jogos Pan-Americanos implicam, entre outros fatores, o uso e na produçáo de lugares relacionados ao turismo e ao entretenimento (como hotéis, restaurantes, museus, casas noturnas) e impulsionam novas oportunidades comerciais. É mister notar que há, sobretudo, uma seletividade espacial no espaço interno da cidade, fazendo com que somente alguns lugares sejam eleitos a inserir-se nesse processo, em que o uso da cultura e do tempo-livre cada vez mais se associa a práticas de consumo. Verifica-se também uma distribuição desigual dos investimentos e ganhos obtidos com os megaeventos nas cidades-sede: intervençôes urbanas pontuais, contemplando determinados fragmentos da cidade (e sua valorização, atendendo a interesses específicos), são normalmente tratadas como de interesse da cidade como um todo.

Os ganhos econômicos concentram-se nas mãos de uma elite já estabelecida, especialmente políticos e empresários (locais e extra-locais), direcionando os investimentos, em sua maior parte públicos, à produção das condiçôes urbanas para sediar o megaevento e, ao mesmo tempo, negligenciando os investimentos públicos que deveriam ser direcionados para o bem-estar social. A própria captação dos megaeventos nas cidades e países é um projeto de uma elite representada por agentes do poder público e do setor privado.

\section{O EMPREENDEDORISMO URBANO NO RIO DE JANEIRO E A CAPTAÇÃO DE MEGAEVENTOS ESPORTIVOS INTERNACIONAIS}

Um novo paradigma relativo à gestão urbana emerge mundialmente na década de 1980 e se consolida no Rio de Janeiro na década de 1990: o planejamento estratégico das cidades, norteando a formulação da política e as estratégias de crescimento urbano. O planejamento estratégico liga-se diretamente ao paradigma do chamado "empreendedorismo urbano", ou seja, uma nova forma de governança urbana caracterizada por uma postura empresarial na gestão das cidades, fortemente apoiada em 
açôes de city-marketing e nas parcerias público-privadas, "tendo como objetivo político e econômico imediato (se bem que, de forma nenhuma exclusivo) muito mais o investimento e o desenvolvimento econômico através de empreendimentos imobiliários pontuais e especulativos do que a melhoria das condiçóes em um âmbito específico" (HARVEY, 1996, p. 53).

O Planejamento Estratégico constituiu mais um mecanismo para inserir o Rio de Janeiro no "mercado mundial de cidades", e é esse também o momento político no qual o Rio de Janeiro, através dos Planos Estratégicos elaborados a partir da década de 1990, utiliza-se da captação de megaeventos esportivos internacionais como estratégia e pretexto às intervençôes urbanas na cidade. O empreendedorismo urbano está, de fato, intimamente relacionado à candidatura do Rio do Janeiro à sede de megaeventos esportivos internacionais, seguindo o exemplo da cidade de Barcelona e utilizando, inclusive, consultoria catalá na elaboração de seu primeiro Plano Estratégico.

Em função das intervençôes urbanas para a ocasião dos Jogos Olímpicos de 1992, Barcelona produziu um "modelo" de urbanismo adotado em diversas cidades no mundo. O chamado "modelo Barcelona” é pautado, basicamente, na requalificação urbana de áreas degradadas, com baixa expressão de centralidade, no aprimoramento no que diz respeito à mobilidade urbana e nas açóes de city-marketing. $\mathrm{O}$ "modelo", que busca também investir na produção de espaços públicos e incentivar áreas de uso misto (residencial, de negócios, cultural), inspirou diversas cidades em diferentes países, independente do fato de serem sedes de um megaevento esportivo internacional.

A postura empreendedora tomada pelos governantes das cidades (e dos países) envolve esforços para a captação desses megaeventos internacionais como mais uma ferramenta para o desenvolvimento urbano e econômico e, ao mesmo tempo, como pretexto às intervençóes urbanas, uma vez que os megaeventos apresentam grande força simbólica capaz de dinamizar, entre outros, a atração de pessoas, capitais e investimentos e de estimular iniciativas de regeneraçáo urbana em determinadas partes das cidades-sede. Esse processo, no dizer de Broudehoux (2007, p. 383), acompanha a produção de um capital simbólico relacionado diretamente com a produção de valor (através da imagem e do espetáculo), envolvendo a construção da imagem positiva da cidade para atrair investimentos de diversas naturezas e visitantes, por meio da remodelação da paisagem urbana para o consumo visual (novas imagens arquitetônicas e ícones urbanos). Assim, o esporte é tratado como negócio e as cidades-sede de megaeventos esportivos um "produto de exportação" e, ao mesmo tempo, "agentes políticos e empreendedores".

As cidades, diante dessa nova forma de governança urbana, são orientadas pela visão de Planos Estratégicos (instrumentos do empreendedorismo urbano), que se traduzem em "intervençôes urbanísticas que apresentam discursos relacionados à dimensão cultural [...] visando, primordialmente, a produção da cidade enquanto negócio. É aí que processos de "revitalização urbana" são, em grande parte, desencadeados pelo reencontro glamouroso entre Cultura (urbana ou náo) e Capital” (ARANTES, 2009, p. 14-15).

O empreendedorismo urbano, no caso carioca, realiza-se através da elaboração, em 1993, do primeiro Plano Estratégico da cidade do Rio de Janeiro (chamado "Rio sempre Rio"), publicado em janeiro de 1996. O Plano foi concebido no primeiro governo municipal de César Maia (1993-1997), que na época contratou a empresa catalã Tecnologies Urbanas Barcelona S.A. (TUBSA) para sua elaboração, seguindo 
o "Modelo Barcelona" de urbanismo, fortemente apoiado na promoção e venda da imagem da cidade através de açóes pontuais de requalificação urbana, visando ressaltar potencialidades da cidade para a atração de investimentos, com base em parcerias público-privadas.

As estratégias visando a atratividade da cidade no contexto do empreendedorismo urbano são pensadas, ainda, em termos de oferta cultural e megaeventos esportivos: no caso carioca, "sustenta-se que as candidaturas [aos Jogos Olímpicos] de 2004, 2012 e 2016, não esquecendo de mencionar os Jogos Pan-Americanos de 2007, inscrevem-se nesse rol de orientaçôes" (BIENENSTEIN et al., 2011, p. 138).

Ao todo, são definidas 7 estratégias (intituladas os "temas-chave" da cidade) que se compóem por 21 objetivos e 61 açóes (agrupadas em 159 projetos), a fim de alcançar o objetivo central do Plano Estratégico - Rio sempre Rio (vago e genérico), que consiste em:

Tornar o Rio de Janeiro uma metrópole com crescente qualidade de vida, socialmente integrada, respeitosa da coisa pública e que confirme sua vocação para a cultura e a alegria de viver. Uma metrópole empreendedora e competitiva, com capacidade para ser o centro de pensamento, de geração de negócios para o país e sua conexão privilegiada com o exterior (PREFEITURA DA CIDADE DO RIO DE JANEIRO, 1996, p. 23).

Das estratégias listadas no Plano, a que merece destaque, por estar relacionada diretamente com o tema deste trabalho, é a intitulada "Rio 2004, pólo regional, nacional e internacional", onde, declaradamente, a cidade é vista como um "produto a ser comercializado" através das açôes de city-marketing, da produção do centro da cidade como um "bem cultural", do incremento do turismo e dos eventos e, por último, prevendo a candidatura do Rio de Janeiro para sediar os Jogos Olímpicos de 2004: é evidenciado, nesse momento, o apoio a megaeventos esportivos internacionais para, basicamente, melhorar a imagem da cidade e ampliar o número de visitantes (o Plano autointitula a cidade como a "única metrópole-resort do mundo"). Conforme essa estratégia, a cidade do Rio de Janeiro "desenvolverá uma série de projetos com prazos definidos e efeitos sobre a sua imagem interna e externa, de modo a se tornar um pólo de atratividade regional, nacional e internacional" (PREFEITURA DA CIDADE DO RIO DE JANEIRO, 1996, p. 52).

O segundo Plano Estratégico (2001-2004), denominado "As cidades da Cidade", dividiu o território municipal em 12 regiôes, privilegiando a "diversidade da cidade" e as "diferentes identidades e potencialidades", criando, dessa forma, um plano estratégico próprio para cada uma delas: "o foco deixou de ser a busca de uma nova identidade para fortalecer a cidade e inseri-la de forma competitiva no cenário mundial" (PREFEITURA DA CIDADE DO RIO DE JANEIRO, 2004, p. 9), passando agora a concentrar-se no desafio de conceber um modelo de desenvolvimento para cada regiáo da cidade. Conforme o Plano, a construção dessa "nova identidade", táo perseguida pelo primeiro Plano Estratégico, surge "em um momento caracterizado por uma considerável baixa na auto-estima geral da população carioca, com a violência, a deterioração das condiçôes de vida e a degradação do espaço urbano causando, entre outras conseqüências, a saída de inúmeras empresas da cidade [...]." (PREFEITURA DA CIDADE DO RIO DE JANEIRO, 2004, p. 18).

Em termos gerais, "os planos estratégicos elaborados para a cidade do Rio de 
Janeiro se expressam, em parte, nas transformaçóes sócio-espaciais presentes na conformaçáo de um novo ordenamento territorial com vistas ao reforço de centralidades antigas, à criação de novas centralidades e à produção de espaços voltados ao consumo elitizado" (RIBEIRO, 2009, p. 45-46). Ainda conforme a autora, o Plano Estratégico II - "As cidades da Cidade", na segunda gestão do Prefeito César Maia (2001-2004), dá-se num momento marcado pela presença de um "sistema de açóes pautado na (des) construção do espaço carioca para a produção de espaços de consumo voltados ao turismo" (RIBEIRO, 2009, p. 46). Nesse momento, todavia, há um elemento novo a orientar o planejamento urbano da cidade do Rio de Janeiro: sua candidatura aos Jogos Pan-americanos de 2007. Assim, o segundo Plano Estratégico mobiliza parcerias com o setor privado com vistas à implementaçáo de um conjunto de obras necessárias à possível realização desse megaevento.

O Plano Estratégico da Prefeitura do Rio de Janeiro (2009-2012) chamado "Pós-2016 - O Rio mais integrado e competitivo", lançado pelo Prefeito Eduardo Paes, situa-se no contexto dos megaeventos esportivos a serem realizados no Brasil: o Rio de Janeiro foi, também, uma das 12 cidades-sede ${ }^{3}$ da Copa do Mundo de 2014 e abrigará os Jogos Olímpicos de 2016. A "visão de futuro" é o lema maior desse Plano, seguindo quatro aspiraçóes principais (social, econômica, ambiental e política), sendo a quarta delas, a política, ligada diretamente aos megaeventos esportivos internacionais; Segundo o documento, o Rio de Janeiro deve:

[...] voltar a ser um importante centro político e cultural tanto no cenário nacional quanto na cena internacional (apoiado nos grandes eventos esportivos internacionais e também consolidar-se como importante centro de debates e conferências internacionais e tornar-se um pólo cultural internacional). (PREFEITURA DA CIDADE DO RIO DE JANEIRO, 2009a, p. 12).

A partir das diretrizes constantes no Plano foram definidas 37 "iniciativas estratégicas", sendo parte destas os projetos "Porto Maravilha", Transcarioca, Transoeste, Ligação C (atualmente chamada Transolímpica) e Vila Olímpica, todos ligados diretamente à produção da "Cidade Olímpica", atualmente em curso no Rio de Janeiro.

\section{A PRODUÇÃO DA “CIDADE OLÍMPICA": DOS JOGOS PAN-AMERICANOS DE 2007 AOS MEGAPROJETOS URBANOS PARA AS OLIMPÍADAS DE 2016}

No ano de 1998, César Maia, à época prefeito da cidade do Rio de Janeiro e responsável pelos Planos Estratégicos, manifestou junto ao Comitê Olímpico Brasileiro (COI) o interesse em sediar os Jogos Pan-americanos de 2007 na cidade ${ }^{4}$. O projeto para sediar os Jogos Pan-americanos de 2007 foi entáo elaborado pela Prefeitura do Rio de Janeiro, em parceria com o COI e, posteriormente, obteve apoio dos governos estadual e federal. A candidatura oficial ocorreu em 2001 com a entrega do dossiê junto à Organização Desportiva Pan-americana (ODEPA) que, em 24 de agosto de 2002, anunciou a vitória do Rio de Janeiro sobre a cidade norte-americana concorrente, San Antonio. O megaevento teve início em 13 de julho de 2007 e ocorreu durante 17 dias,
3 Juntamente com Belo Horizonte, Brasília, Cuiabá, Curitiba, Fortaleza, Manaus, Natal, Porto Alegre, Recife, Salvador e São Paulo.
40 Rio de Janeiro foi a única cidade brasileira, nesse momento, a demonstrar interesse na candidatura. 
5 Totalmente reformado para o Pan-2007, onde se deram as cerimônias de abertura e encerramento do megaevento.

6 Conforme o Relatório Oficial dos XV Jogos Pan -americanos e III Jogos Parapan-americanos Rio 2007 (COMITÊ OLÍMPICO BRASILEIRO, 2009).

7 Segundo Raeder (2010, p. 117), "Em virtude dos Jogos Olímpicos de 2016 o Autódromo dará lugar às instalações planejadas para o evento. Um novo Autódromo deverá ser construído em outro ponto da Cidade".

80 Parque Aquático Maria Lenk e o Velódromo são administrados pelo Comitê Olímpico Brasileiro (até 2028) e a Arena Olímpica (atual HSBC Arena) é administrada pela GL Events através de contrato de cessão de uso e manutenção até 2016.

9 Compreendendo 17 edificios e 1.480 apartamentos, ocupando uma área de 340 mil m2.

10 Elaborado em 2009 pelo Comitê Olímpico Brasileiro, Prefeitura do Rio de Janeiro, Governo do Estado do Rio de Janeiro e Governo Federal (Ministério do Esporte) (COMITÊ OLÍMPICO BRASILEIRO, 2009). concentrando 5.662 atletas de 42 países de todo o continente americano. Ao todo, foram definidas quatro áreas ("regiôes") para a realização do evento na cidade (Pão de Açúcar, Maracanã, Deodoro e Barra) e, consequentemente, onde se daria a localização dos equipamentos esportivos.

A regiáo do Pão de Açúcar concentrou instalaçôes temporárias e ao ar livre na Praia de Copacabana e o uso de instalaçóes permanentes pré-existentes e adaptadas, como o Clube Caiçaras (situado na Lagoa Rodrigo de Freitas), a Marina da Glória, o Parque do Flamengo e o Estádio de Remo da Lagoa. A região do Maracanã concentrou os dois estádios utilizados nesse megaevento: o Estádio do Maracanā ${ }^{5}$ e o Estádio João Havelange (conhecido como Engenhão, por estar situado no bairro de Engenho de Dentro), construído especialmente para os Jogos Pan-Americanos de 2007, com capacidade para abrigar 45.000 expectadores das provas de atletismo e futebol. Localizada na Zona Oeste da cidade, a regiāo Deodoro abrigou basicamente o Complexo Esportivo Deodoro, situado na Vila Militar, em área pertencente ao Exército Brasileiro.

Contudo, não houve um equilíbrio na distribuiçẫo dos investimentos e intervençôes nessas diferentes áreas, e a concentração se deu majoritariamente na região da Barra da Tijuca. Essa área, definida como "o coração dos jogos" ", foi o principal polo das competiçôes e abrigou as seguintes instalaçôes: 1) Complexo Cidade dos Esportes, construído numa parte do Autódromo Internacional Nelson Piquet ${ }^{7}$, contendo a Arena Multiuso (ou Arena Olímpica), o Parque Aquático Maria Lenk e o Velódromo 2) Complexo Esportivo Riocentro, compreendendo instalaçôes temporárias nos cinco pavilhóes do maior centro de convençôes, feiras e exposiçóes da América Latina (Riocentro); 3) Clube Marapendi, adaptado para as provas de tênis; 4) Morro do Outeiro, com instalaçôes temporárias de pistas de mountain bike e BMX (outra disciplina do ciclismo); 5) Cidade do Rock, terreno situado junto ao Riocentro preparado em 1985 para abrigar o Rock in Rio (1985) e utilizado no Pan-2007 como campo de beisebol e softbol; 6) Barra Bowling, equipamento instalado desde 1993 no Barra Shopping, utilizado nas provas de boliche; e 7) Centro de Futebol Zico, localizado no Recreio dos Bandeirantes.

A região da Barra, além de concentrar a maioria das instalaçóes esportivas, abrigou a Vila Pan-americana ${ }^{9}$, mais uma estratégia do poder público dirigida a uma área ocupada em grande parte por população de média e alta renda e, em cumplicidade com a iniciativa privada, para dinamizar o mercado imobiliário. Historicamente, os esforços para a ocupaçáo e valorizaçáo dessa área remontam ao final dos anos 1960, e a mesma encontra-se em processo ininterrupto de urbanizaçáo desde o Plano Piloto da Barra da Tijuca, de 1969. Segundo Raeder (2010, p. 89), a escolha da Barra da Tijuca "deve ser contextualizada no movimento de deslocamento de algumas empresas cariocas do Centro para aquela área, [e esses novos investimentos significam] a aposta no desenvolvimento desta área como uma nova centralidade da cidade para negócios e atividades do terciário superior".

O Relatório Oficial dos XV Jogos Pan-americanos e III Jogos Parapan-americanos Rio $2007^{10}$ apontou alguns legados decorrentes desse megaevento na cidade do Rio de Janeiro. Entre eles destacam-se as melhorias na área de segurança (formaçấo de pessoas, compra de equipamentos, etc.) e no sistema viário nos arredores das instalaçôes esportivas, a projeção internacional da cidade e a construção de novos hotéis (além de reformas e ampliaçôes de estabelecimentos já existentes). As próprias 
instalações esportivas construídas na cidade (ou as pré-existentes adaptadas) também constituíram legados apontados pelo Relatório, especialmente a Cidade dos Esportes, na Barra da Tijuca ${ }^{11}$. No bairro de Engenho de Dentro, em decorrência da construção do Estádio João Havelange, houve, como legado apontado no Relatório, a valorização dos imóveis e a atração de novos empreendimentos imobiliários e negócios ${ }^{12}$, acarretando assim uma suposta dinamização econômica da região, altamente populosa (chamada "Grande Méier") e economicamente estagnada, conforme o referido documento. Com relação aos legados decorrentes do Complexo Deodoro, o mesmo relatório cita somente, de forma genérica, que houve a dinamização do fluxo de pessoas nessa área (relativamente distante) da cidade na ocasião dos Jogos, dinamizando o comércio e os serviços.

Por outro lado, o Tribunal de Contas da Uniáo (TCU) elaborou, em 2008, o Relatório de Acompanhamento das Açóes e Obras relacionadas aos Jogos Pan e Parapan-americanos de 2007, cuja avaliação final das açôes realizadas foi relatada pelo Ministro Marcos Vinícius Vilaça (BRASIL, 2008). Dentre os diversos apontamentos, destaca-se o superfaturamento: a estimativa inicial dos gastos feita em 2001 pela Fundação Getúlio Vargas (FGV) era de US\$ 224 milhóes e, ao final, o custo aproximado foi de R \$ 3,3 bilhôes aos cofres públicos das três esferas de governo envolvidas (municipal, estadual e federal). Um dos principais motivos diz respeito ao atraso no cronograma de execução das obras, o que acarretou em custos extras para que as construçóes ficassem prontas a tempo. Cálculos posteriores indicaram um valor ainda maior do custo total: cerca de R \$ 3,7 bilhôes, representando os Jogos Pan-americanos mais caros da história, segundo Sánchez e Bienenstein (2009). A participação da iniciativa privada foi de pouca relevância no evento (cerca de $20 \%$ do custo total), desmistificando, assim, o papel das parcerias público-privadas na produção do espaço interno da metrópole sede de megaeventos esportivos internacionais.

Segundo o Relatório supracitado, a única parceria público-privada (PPP) para a construção de parte da infraestrutura para os Jogos se deu na Vila Pan-americana, construída através de empréstimo feito pela Caixa Econômica Federal e depois explorada comercialmente no mercado imobiliário como um condomínio residencial pela Agenco Engenharia e Construçóes S.A., empresa que investe na Barra da Tijuca desde a década de 1990. A responsabilidade da Prefeitura do Rio de Janeiro consistiu em dotar a área de toda a infra-estrutura necessária, como a urbanização das ruas do entorno da Vila Pan-americana, a implantação de estações de tratamento de esgoto, iluminação pública e canalizações, além da realização de alteraçôes urbanísticas na área, permitindo, além das construçôes da Vila e de estabelecimentos com fins esportivos, "a construção de estabelecimentos comerciais, residenciais, hoteleiros, de lazer e diversão, com gabarito de construção de 12 pavimentos (e 22 para edifícios residenciais)" (PREFEITURA DA CIDADE DO RIO DE JANEIRO, 2005).

A Vila Pan-americana teve grande sucesso de vendas no mercado imobiliário após os Jogos e constituiu mais um empreendimento semelhante aos vários condomínios de apartamentos existentes na Barra da Tijuca; esse projeto ocupou um terreno que, "além de apresentar diversos problemas que redundaram na necessidade de onerosas melhorias ${ }^{13}$, encontra-se num dos principais eixos de expansão imobiliária do Rio de Janeiro, reforçando ainda mais a valorização de uma área da cidade já valorizada" (SÁNCHEZ; BIENENSTEIN, 2009, p. 14). Sendo assim, a Vila Pan-Americana não foi utilizada, posteriormente, como lugar de habitaçôes populares.
110 Relatório trata a Cidade dos Esportes como sendo um novo vetor de desenvolvimento para aquela área da cidade, tendo em vista a presença dos equipamentos esportivos e da indústria do entretenimento, exemplificada pelo caso da Arena Olímpica (atualmente HSBC Arena, uma casa de espetáculos).

12 A valorização no entorno das novas instalações esportivas, notadamente o Estádio Olímpico João Havelange e o Complexo Cidade dos Esportes, foi calculada em R\$ 1 bilhão, conforme o Relatório (COMITÊ OLÍMPICO BRASILEIRO, 2009, p. 218).

13 Trata-se de terreno turfoso, úmido, tendo sido necessários cerca de cinquenta metros de fundação, que encareceram ainda mais sua construção. 
14 Não ocorreu, portanto, no bairro em sua totalidade, como divulgado no projeto inicial.

15 Expressão utilizada por Bienenstein et al. (2011).

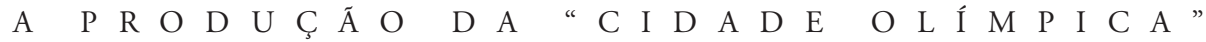

Outra questáo relevante diz respeito ao pequeno legado à cidade, em termos de infraestrutura urbana decorrentes dos Jogos. Houve uma ampla produção de discursos a respeito da realização do evento, todos visando a legitimação das ações em nome dos legados que este deixaria na cidade em prol dos habitantes, como os benefícios ambientais, as melhorias na infraestrutura urbana, no desenvolvimento econômico e social, a geração de empregos e dinamização do turismo, entre outros.

No caso do estádio de futebol "Engenhão", além do legado do próprio equipamento esportivo em si, houve a revitalização urbana restrita aos arredores do mesmo ${ }^{14}$ e o surgimento de novos empreendimentos imobiliários que, através do valor simbólico atrelado ao Estádio, utilizaram-no como estratégia de marketing para a venda de imóveis (SÁNCHEZ; BIENENSTEIN, 2009). A dinamização do comércio local também foi pouco significativa, em oposição ao discurso inicial (dos planejadores) que anunciava maior dinamismo ao comércio e aos serviços do bairro através da instalaçáo do Estádio.

No projeto do Pan-2007 era mencionada a intenção de lidar com questôes de pobreza e exclusão social existentes na cidade através do esporte. Porém, poucos foram os benefícios sociais decorrentes dos legados do Pan, uma vez que grande parte dos equipamentos passou à iniciativa privada, por concessão do poder público municipal, e boa parte deles encontra-se subutilizados. Alguns movimentos de resistência surgiram nesse contexto, tanto na forma de manifestaçóes (como as que ocorreram contra as obras e as tentativas de descaracterizaçáo e privatização da Marina da Glória e do Parque do Flamengo) como também na criação do Comitê Social do Pan (CSP), articulação da sociedade civil criada em 2005 e ligada ao acompanhamento dos gastos públicos, à crítica sobre a realização dos Jogos e suas repercussóes sociais na cidade.

Apesar das contradiçôes socioespaciais decorrentes dos Jogos Pan-americanos e das diversas questóes explicitadas anteriormente, o megaevento contribuiu, de certa maneira, para a inserção da cidade do Rio de Janeiro no "mercado mundial dos megaeventos esportivos" 15 no século XXI e, assim, à vitória da cidade para sediar, finalmente, uma Olimpíada. Considerado "exitoso" por parte de seus organizadores, o evento foi pensado desde o início visando a candidatura da cidade para sediar os Jogos Olímpicos num futuro próximo: na verdade, a produção da cidade para a realização de um megaevento esportivo como o Pan deveria torná-la uma "vitrine", uma cidade apta para abrigar uma Olimpíada, foco principal desde a elaboração do primeiro Plano Estratégico do Rio de Janeiro (1993).

Ao final do seu terceiro mandato como prefeito da cidade do Rio de Janeiro, César Maia promulgou o Decreto 29.398, de 09 de julho de 2008, criando o Comitê Especial de Legado Urbano (CELU) de apoio à candidatura do Rio de Janeiro às Olimpíadas de 2016, responsável pela elaboração de um projeto urbanístico para acolher os Jogos Olímpicos de 2016 e concluído em outubro de 2008, intitulado "Plano de Legado Urbano e Ambiental Rio-2016", ou simplesmente "Plano Rio-2016", apresentando em seu conteúdo propostas de intervençôes públicas e possíveis legados urbanos decorrentes da realização do megaevento na cidade (PREFEITURA DA CIDADE DO RIO DE JANEIRO, [s.d.]).

O mandato do prefeito César Maia terminou em 01 de janeiro de 2009 com a posse do entáo prefeito eleito, Eduardo Paes. Naquele momento (janeiro de 2009), foi entregue ao Comitê Olímpico Internacional (COI) a versão final do Dossiê de candidatura do Rio de Janeiro à sede dos Jogos Olímpicos e Para-Olímpicos de 2016, 
e o anúncio da sua vitória se deu em 02 de outubro de 2009, em Copenhague, quando tinha como concorrente final a cidade de Madri. O Rio de Janeiro teve anteriormente duas tentativas frustradas, referentes às candidaturas para sediar os Jogos Olímpicos de 2004 e 2012. Em 1999, ao invés de ser candidata aos Jogos Olímpicos de 2008, a cidade centrou-se na candidatura aos Jogos Pan-Americanos de 2007.

O dossiê final, que atualmente orienta a produção da "Cidade Olímpica", organiza a cidade em quatro zonas (Barra, Copacabana, Maracanã e Deodoro) e pouco difere do plano anteriormente concebido para os Jogos Pan-americanos de 2007. Esse fato já era previsto, uma vez que o Pan-2007 foi pensado tendo em mente a realização de uma Olimpíada na cidade do Rio de Janeiro num futuro próximo, o que de fato vai ocorrer. Indiscutivelmente, um dos principais legados dos Jogos Pan-americanos de 2007 foi a representação simbólica desse evento, que se traduziu numa jogada de marketing para a eleiçâo da cidade como sede dos Jogos Olímpicos de 2016.

Repercussóes espaciais dos Jogos Olímpicos sobre a produção do espaço urbano carioca devem ser potencializadas comparativamente às repercussōes do Pan-2007, dada a magnitude do primeiro em relação ao segundo. Para 2016, conforme o website oficial do evento, "são esperados mais de 10.500 atletas de cerca de 205 nações ao redor do mundo, além de milhares de profissionais de imprensa, de apoio, apaixonados pelo esporte e turistas de todos os cantos do globo" (OS JOGOS, [s.d.]) $)^{16}$. A estimativa dos gastos apresentada no Dossiê de Candidatura aos Jogos Olímpicos de 2016 corresponde ao valor de $\mathrm{R} \$ 28,9$ bilhóes, cerca de oito vezes mais que os investimentos em decorrência dos Jogos Pan-americanos de 2007 (R \$ 3,7 bilhôes), tendo novamente o predomínio dos recursos públicos na totalidade dos investimentos.

No que diz respeito à reestruturação urbana que está sendo levada a cabo no Rio de Janeiro em decorrência dos Jogos Olímpicos de 2016 (além dos projetos viários e das intervençóes na Barra da Tijuca), talvez a novidade maior seja a atenção dada atualmente à zona portuária da cidade, cujo fato não ocorreu na época das preparaçôes para os Jogos Pan-americanos de 2007. As ações da Prefeitura do Rio de Janeiro se intensificam nas políticas urbanas voltadas à região central e à zona portuária, cuja expressão maior é representada pelo Projeto de Revitalização da Zona Portuária da cidade, intitulado Porto Maravilha (2009) ${ }^{17}$, projeto inserido em um movimento mundial de requalificação urbana de zonas portuárias.

O Porto Maravilha pretende, declaradamente, criar uma nova área de centralidade no Rio de Janeiro e tornar-se uma das maiores oportunidades de valorização patrimonial da cidade, intimamente relacionado à dinamização do mercado imobiliário e ao desenvolvimento do turismo, comércio e entretenimento, através da recuperação do patrimônio histórico e cultural existente e da implantação de novos equipamentos, estimulando, inclusive, usos mistos. O projeto prevê, além do "embelezamento" através de melhorias infraestruturais e projetos viários e de transporte, a construção, através de parceria público-privada, do Museu Olímpico, da Pinacoteca do Rio, do Museu de Arte do Rio de Janeiro (nas antigas dependências do edifício da Polícia Federal, na Praça Mauá), do AquaRio (projetado para ser o maior aquário marinho da América Latina) e do Museu do Amanhā, no Píer Mauá.
16 Vale ressaltar que o Rio de Janeiro sediou os Jogos Mundiais Militares em 2011, a Copa das Confederações em 2013 e é uma das 12 cidadessede da Copa de 2014, o que demonstra sua inserção na rota dos eventos esportivos internacionais.

170 Prefeito Eduardo Paes, em 23/11/2009 sancionou a lei que institui a "Operação Urbana Consorciada da Região do Porto do Rio", viabilizando o projeto de revitalização da região através de alterações dos parâmetros urbanísticos (MOURA, 2009). 
18 Em referência, entre outros, aos habitantes do Morro da Conceição e do Morro da Providência, situados nas imediações do Porto do Rio de Janeiro.
Figura 1: Perspectiva futura do Museu do Amanhã, no Píer Mauá

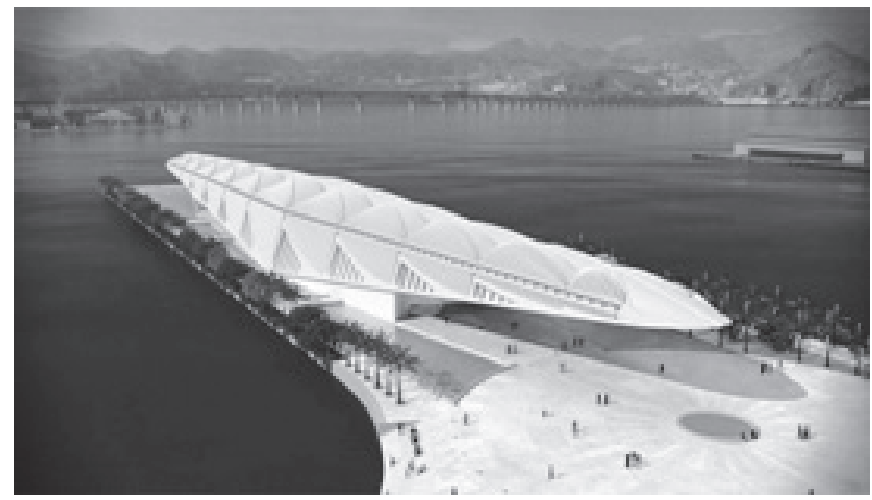

Fonte: Prefeitura (2012).

O projeto Porto Maravilha prevê ainda a instalação de linha de veículo leve sobre trilhos (VLC), conectando a área do núcleo central do Rio e propiciando a "devolução" da vista da Baía de Guanabara à populaçáo através da demolição de parte do elevado da Avenida Perimetral, sobre a Praça Mauá, além de incentivos visando à atração de hotéis, bares, restaurantes, empresas e edifícios residenciais (alteraçōes na legislação urbanística da zona portuária e arredores são assim realizadas, a fim de estimular estas e demais edificaçôes). Na área portuária, estima-se que $75 \%$ das terras sejam públicas, mas, ao invés de serem utilizadas para a construção de habitação de interesse social, são direcionadas a operaçôes imobiliárias. Trata-se, ainda, de um projeto de gentrificação dessa área "e não da recuperação de sua infra-estrutura para os que ali habitam e no reforço de sua identidade cultural" (BIENENSTEIN et al., 2011, p. 150) ${ }^{18}$.

As intervençôes referentes à primeira fase do Projeto Porto Maravilha são financiadas com recursos públicos e representam um investimento total da Prefeitura no valor aproximado de $\mathrm{R} \$ 200$ milhóes. $\mathrm{Na}$ fase 2 , os recursos serão oriundos da iniciativa privada por meio de Operação Urbana Consorciada e, conforme noticiado no Portal 2014, o consórcio Porto Novo (formado pelas empresas Odebrecht, OAS e Carioca Engenharia) foi o vencedor da PPP referente à segunda fase do Projeto, que custará R \$ 7,3 bilhóes (VENCEDOR, 2010). Está prevista a conclusão do Projeto para o final de 2015 e, já em sua fase inicial, presencia-se a valorização do preço dos imóveis no Centro do Rio e na zona portuária, como constatado no mês de agosto de 2011 em pesquisa feita pelo Sindicato de Habitação do Rio (Secovi-Rio): "o metro quadrado no Centro valorizou 63,57\% para a venda, passando de $\mathrm{R} \$ 3.338$ para $\mathrm{R} \$ 5.460$, na comparação com o mesmo mês em 2010. Quando se fala de aluguel, a variação em igual período foi de $58,32 \%$, com o metro quadrado saltando de $\mathrm{R} \$ 13,94$ para $\mathrm{R} \$$ 22,07 (NOGUEIRA, 2011). 
Figura 2: Vista aérea de parte da Zona Figura 3: Perspectiva futura da nova Praça Portuária (Praça Mauá e Pier Mauá), em 2010

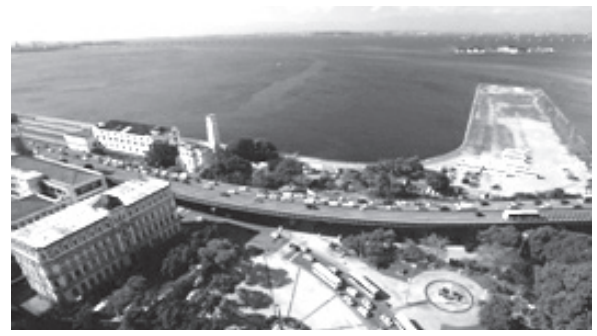

Fonte: Nogueira (2011).
Mauá

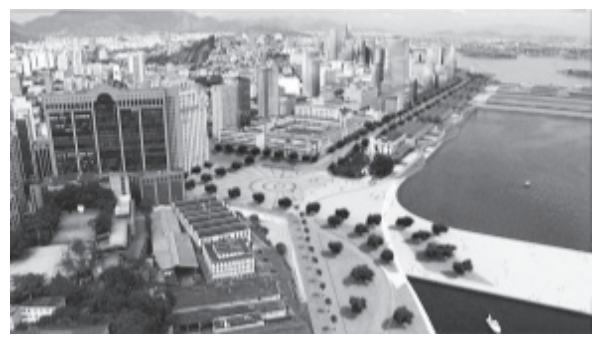

Fonte: Prefeitura da Cidade do Rio de Janeiro ([2009?]).

A Zona Sul do Rio de Janeiro, especialmente Copacabana, também se insere no contexto da produção da cidade para a venda no mercado internacional, na competitividade entre as cidades e na atraçâo por investimentos e turistas, como pode ser atualmente constatado pela construção do Museu da Imagem e do Som (MIS), um "ícone arquitetônico do século XXI" em plena orla marítima, na Avenida Atlântica (SETE, 2009). Esse megaprojeto na cidade conta com parceria entre o governo do estado e a Fundação Roberto Marinho, envolve cerca de R \$ 70 milhóes $^{19}$ e está situado no local onde funcionava a antiga boate Help, um símbolo da prostituição no bairro por mais de 25 anos (RODRIGUES; WERNECK, 2009), associada também ao tráfico de drogas. Nesse sentido, pretende-se minimizar a imagem negativa de Copacabana, incentivando-se a ocupação comercial e a construção de atrativos culturais. O novo MIS, concebido pelo escritório Diller Scofidio, foi projetado pela arquiteta norte-americana Elizabeth Diller e, assim como o Museu do Amanhã, em construção na zona portuária do Rio de Janeiro, insere-se na lógica das "construçóes espetaculares", cujo foco referese diretamente à produção (ou ressignificação) da imagem da cidade.

Outra medida de destaque relacionada aos Jogos Olímpicos de 2016 refere-se à mobilidade urbana na cidade, na qual se verificam alguns projetos, como a reforma dos dois terminais do Aeroporto Internacional Tom Jobim, a ampliação do terminal de passageiros no Porto do Rio de Janeiro, a construção de 3 novos píeres de atracação, melhorias nos serviços de ônibus e na rede ferroviária do subúrbio e a extensão da linha do metrô desde a Zona Sul à Barra da Tijuca, onde se encontra em construção a Estação Jar-

Figura 4: Perspectiva do Museu da Imagem e do Som, na orla de Copacabana

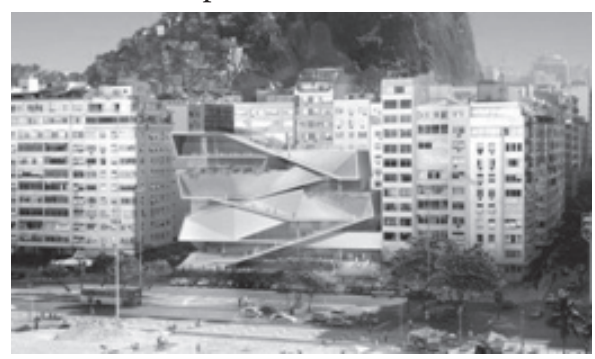

Fonte: Uchôa (2010).
19 Desse total, o Governo do Estado do Rio de Janeiro investirá $\mathrm{R} \$ 50$ milhões. dim Oceânico.

Para a dinamização do fluxo de pessoas durante a realização desse megaevento, três megaprojetos viários encontram-se em fase de execução no Rio de Janeiro: são as chamadas Transcarioca, Transolímpica e Transoeste. Boa parte das obras relativas a esses megaprojetos viários é financiada pelo governo federal e de responsabilidade da Prefeitura Municipal do Rio de Janeiro, por vezes em parceria com a iniciativa privada, 
20 Informações obtidas no Contrato 007/2011, disponível em <http://www. copatransparente.gov.br/ acoes/corredor-brt-transcarioca-etapa-1-barra-penha/ contrato-ndeg007-2011>. O orçamento previsto para a Transcarioca é de $\mathrm{R} \$ 1,6 \mathrm{bi}$ Ihão e, em abril de 2012, a empresa Delta Construções S/A deixa o consórcio.

210 orçamento aproximado é de $R \$ 800$ milhões.

22 Outro projeto, a Transbrasil, está em fase de concepção e ocupará trechos da Avenida Brasil. A intenção é ligar o Aeroporto Santos Dumont a Deodoro, na Zona Norte, em uma extensão aproximada de $32 \mathrm{~km}$.

23 A Vila Olímpica contará com 34 edifícios de 12 andares, com 2.448 apartamentos de três e quatro dormitórios.

A P R O D U Ç

como é o caso da Transolímpica. Consistem, basicamente, em três grandes eixos viários implantados ora em vias já existentes (reformadas e/ou ampliadas), ora em novas vias, envolvendo também a construção de túneis, pontes, viadutos e mergulhóes e a implantaçáo de corredores de ônibus articulado utilizando o Bus Rapid Transit (BRT).

A Transcarioca fará a ligação entre a Barra da Tijuca, no Terminal Alvorada, e o Aeroporto Internacional Tom Jobim (Galeão), passando pelos bairros de Madureira e Penha (Zona Norte). Terá uma extensão aproximada de $38 \mathrm{~km}$, envolvendo a desapropriação de cerca de 3.630 imóveis nos bairros de Jacarepaguá e Madureira. As obras são executadas pelo Consórcio Transcarioca BRT, constituído pelas empresas Construtora Andrade Gutierrez S/A e Delta Construçóes S/A²0.

O Complexo Cidade dos Esportes e a Vila Olímpica, na Barra da Tijuca, serão interligados ao Complexo Esportivo Deodoro através de outro eixo viário, a Transolímpica, que percorrerá um trecho aproximado de $26 \mathrm{~km}$ de extensão, começando no cruzamento da Avenida das Américas e Avenida Salvador Allende, na Barra. O projeto prevê, inicialmente, cerca de 1.271 desapropriaçôes e será construído pelo Consórcio Rio Olímpico, representado pelas empresas Invepar, CCR e Odebrecht, que do orçamento total de $\mathrm{R} \$ 1,55$ bilhão custeará $\mathrm{R} \$ 479$ milhóes, cabendo à Prefeitura do Rio de Janeiro arcar com $\mathrm{R} \$ 1.072$ bilhão.

A Transoeste, terceiro projeto viário ${ }^{21}$, fará conexão com a futura estação de metrô (Jardim Oceânico), com a Transcarioca e a Transolímpica, e ainda ligará a Barra da Tijuca aos bairros de Santa Cruz e Campo Grande, no extremo da Zona Oeste, numa extensão total aproximada de $56 \mathrm{~km}^{22}$. O intuito desses megaprojetos viários é, portanto, investir na fluidez territorial de pessoas para a Barra da Tijuca, "aproximando" esse bairro do restante da cidade.

Além da ampliação e adequação dos equipamentos esportivos existentes na Barra da Tijuca, outro destaque na produção da "Cidade Olímpica" é a construção da Vila de Mídia e Vila Olímpica ${ }^{23}$ (por vezes chamada de Vila dos Atletas). Situadas em terrenos pertencentes à construtora Carvalho Hosken, constituem-se, assim como a Vila Pan-americana, em novos empreendimentos imobiliários a assumir, após os Jogos, um caráter residencial privado. A Carvalho Hosken é a empresa responsável pela construçáo desses empreendimentos, assim como sua comercialização após o megaevento. Conforme explicitado pelas linhas anteriores, boa parte das açôes concentra-se na ocupação e valorização dessa área, como também no reforço de centralidade da Barra da Tijuca, algo também verificado na ocasião dos Jogos Pan-Americanos de 2007.

\section{CONSIDERAÇÕES FINAIS}

As açôes presentes no período atual são responsáveis pela introdução de um novo sistema de objetos na cidade do Rio de Janeiro, coerente com a lógica empresarial de administraçáo urbana. O impacto sobre o ambiente urbano construído ocorre na medida em que essa produção volta-se para o objetivo de melhorar a posição competitiva da cidade na divisão espacial do consumo e na tentativa de atrair investimentos.

O caráter empresarial, que se traduz numa nova postura de administraçáo urbana, reflete-se diretamente numa nova dinâmica de organização do espaço interno da metrópole, imprimindo uma lógica espacial que tende a "forçar a reprodução repetitiva e em série de certos padróes de empreendimentos" (HARVEY, 1996, p. 56), o 
que implica um novo processo de renovação urbana que realça a importância da qualidade do espaço. Na produçáo da cidade, lógicas espaciais dos megaeventos tendem a prevalecer, destacando-se possibilidades de valorização do solo urbano e captação de investimentos, com nítido favorecimento do setor de construção civil. Trata-se de uma orientação mercadófila, seguida fielmente pelo projeto olímpico no Rio de Janeiro.

É nesse contexto que se inserem, portanto, as açôes levadas a cabo no Rio de Janeiro para a produção da "Cidade Olímpica", que envolvem megaprojetos como o Porto Maravilha, a Transcarioca, a Transoeste, a Transolímpica, assim como outras obras em curso (como a construção de novos museus, da Vila Olímpica, etc.), que exemplificam a lógica empresarial presente na produção do espaço urbano aliada, na história do presente, aos megaeventos esportivos internacionais realizados na cidade. Exemplificam, ainda, uma reestruturação urbana a partir da produção de novas formas, da refuncionalização de formas pretéritas, dos novos usos de parcelas do espaço e, por fim, da produção de novas áreas (valorizadas) na cidade, acentuando assim processos de fragmentação espacial e centralidade urbana.

\section{REFERÊNCIAS BIBLIOGRÁFICAS}

AHLFELDT, G.; MAENNIG, W. Arenas, arena architecture and the impact of location desirability: the case of 'Olympic arenas' in Prenzlauer Berg, Berlin. Urban Studies, v. 46, n. 7, p. 1343-1362, jun. 2009.

ARANTES, O. Uma estratégia fatal: a cultura nas novas gestôes urbanas. In: ; VAINER, C.; MARICATO, E. A cidade do pensamento único: desmanchando consensos. 5. ed. Petrópolis: Vozes, 2009. p. 11-74.

BENEDICTO, D. B. M. Desafiando o coro dos contentes: vozes dissonantes no processo de implementação dos Jogos Pan-americanos, Rio 2007. In: ENCONTRO NACIONAL DA ANPUR, 13, 2009, Florianópolis. Anais do XIII Encontro Nacional da Anpur. Florianópolis: ANPUR, 2009.

BIENENSTEIN, G. et al. Megaeventos e metrópoles: G.; BIENENSTEIN, G.; SÁNCHEZ, F. (Org.). O jogo continua: megaeventos esportivos e cidades. Rio de Janeiro: EdUERJ, 2011. p. 123-161.

BRASIL. Tribunal de Contas da União. Relatório de Acompanhamento das Açóes e Obras relacionadas aos Jogos Pan e Parapan-americanos de 2007. Relator: Marcos Vinícius Vilaça. Brasília: TCU, 2008. Disponível em: < <http://portal2.tcu.gov.br/portal/page/portal/TCU/ imprensa/noticias/noticias_arquivos/Pan.doc>. Acesso em $02 \mathrm{dez} 2011$.

BROUDEHOUX, A-M. Spectacular Beijing: the conspicuous construction of an olympic metropolis. Journal of Urban Affairs, v.29, n.4, p. 383-399, oct. 2007.

CARLOS, A. F. A. A natureza do espaço fragmentado. In: SANTOS, M.; SOUZA, M. A.; SILVEIRA, M. L. Território: globalização e fragmentaçáo. 5. ed. São Paulo: Hucitec, 2002. p. 191-197.

COMITÊ OLÍMPICO BRASILEIRO. RELATÓRIO Oficial dos XV Jogos Pan Americanos e III Jogos Parapan-Americanos Rio 2007. Rio de Janeiro: Prefeitura da Cidade do Rio de Janeiro; Governo do Estado do Rio de Janeiro; Brasília: Ministério do Esporte, 2009. Disponível em: <http://www.esporte.gov.br/arquivos/publicacoes/panVolume1.pdf>. Acesso em: 26 set. 2014.

HARVEY, D. Do gerenciamento ao empresariamento: a transformação da administração urbana no capitalismo tardio. Espaço e Debates, v. 16, n. 39, p. 48-64, 1996. . A produção capitalista do espaço. 2. ed. São Paulo: Annablume, 2005.

\begin{abstract}
Fabio Silveira Molina é geógrafo, mestre e doutor em Geografia Humana pela Universidade de São Paulo (USP); assistente técnico de direção junto à Comissão de Cooperação Internacional e Nacional da Faculdade de Direito da USP, Brasil. E-mail:fmolina@usp.br.
\end{abstract}

Artigo recebido em março de 2014 e aprovado para publicação em julho de 2014. 
INDOVINA, F. Os grandes eventos e a cidade ocasional. In: FERREIRA, V. M.; INDOVINA, F. (Org.). A cidade da EXPO '98: uma reconversão na frente ribeirinha de Lisboa? Lisboa: Bizâncio, 1999, p. 126-143.

MOLINA, F. S. Megaeventos e produção do espaço urbano no Rio de Janeiro: da "Paris dos Trópicos" à "Cidade Olímpica”. 2013. 214 f. Tese (Doutorado em Geografia Humana) Faculdade de Filosofia, Letras e Ciências Humanas da Universidade de São PauloSão Paulo, 2013.

MOURA, P. Projeto para revitalizar área do Porto avança no Rio. Valor Econômico, Rio de Janeiro, 24 nov. 2009. Disponível em: <http://www.valor.com.br/arquivo/795443/projeto-para-revitalizar-area-do-porto-avanca-no-rio>. Acesso em 26 set. 2014.

NOGUEIRA, R. Imóveis na região central do Rio já têm o preço da modernização. Extra Online, Rio de Janeiro, 11 set. 2011. Disponível em: <http://extra.globo.com/casa/imoveisna-regiao-central-do-rio-ja-tem-preco-da-modernizacao-2609573.html>. Acesso em: 26 set. 2014.

OS JOGOS Olímpicos. Rio de Janeiro: Jogos Olímpicos Rio 2016, [s.d]. Disponível em: <http://www.rio2016.org.br/os-jogos/olímpicos>. Acesso em: 26 set. 2014.

PREFEITURA do Rio apresenta projeto do Museu do Amanhã. Veja, São Paulo, 2 maio 2012. Disponível em: <http://veja.abril.com.br/noticia/brasil/prefeitura-do-rio-apresenta-projeto-do-museu-do-amanha>. Acesso em: 26 out. 2014.

PREFEITURA DA CIDADE DO RIO DE JANEIRO. Plano Estratégico da Cidade do Rio de Janeiro - Rio sempre Rio. Rio de Janeiro: Prefeitura da Cidade do Rio de Janeiro, 1996. Plano Estratégico da Cidade do Rio de Janeiro - As cidades da Cidade. Rio de Janeiro: Prefeitura da Cidade do Rio de Janeiro, 2004.

. Instituto Pereira Passos. Cidade apresenta maior capacidade de investimento no Brasil. Rio de Janeiro: Prefeitura da Cidade do Rio de Janeiro, Instituto Pereira Passos, Diretoria de Informações Geográficas, jan. 2005. (Coleção Estudos da Cidade). Disponível em: <http://www.armazemdedados.rio.rj.gov.br/arquivos/115_cidade\%20apresenta\%20 maior\%20capacidade\%20de\%20investimento.PDF>. Acesso em: 26 out. 2014.

Plano Estratégico da Prefeitura do Rio de Janeiro - Pós 2016, o Rio mais integrado e competitivo. Rio de Janeiro: Prefeitura da Cidade do Rio de Janeiro, 2009a.

- Dossiê de candidatura do Rio de Janeiro à sede dos Jogos Olímpicos e Para-Olímpicos de 2016. Rio de Janeiro: Prefeitura da Cidade do Rio de Janeiro, 2009b. Disponível em: <http://www.jogosolimpicos2016.com/sites/default/files/parceiros/dossie_de_candidatura_v1.pdf>. Acesso em: 26 set. 2014.

Projeto Porto Maravilha. Rio de Janeiro: Prefeitura da Cidade do Rio de Janeiro, [2009?]. Disponível em: <http://www.camara.rj.gov.br/planodiretor/pd2009/porto2009/aud_public_porto_maravilha.pdf>. Acesso em: 26 out. 2014.

Secretaria Municipal de Urbanismo. Comitê Especial de Legado Urbano. Plano de Legado Urbano e Ambiental: Olimpíadas Rio 2016. Rio de Janeiro: Prefeitura da Cidade do Rio de Janeiro, [s.d].

RAEDER, S. Jogos \& cidades: ordenamento territorial urbano em sedes de megaeventos esportivos. Brasília: Ministério do Esporte, 2010.

RIBEIRO, V. M. F. A (des)construção do espaço carioca na "Era César Maia" (1993-2008): reflexóes sobre o modelo de planejamento urbano estratégico e o conjunto de objetos arquitetônicos denominado "Pentágono do Milênio". 2009. 353f. Tese (Doutorado em Planejamento Urbano e Regional) - Instituto de Pesquisa e Planejamento urbano e Regional, Universidade Federal do Rio de, 2009.

RODRIGUES, A.; WERNECK, F. Boate que dará lugar ao projeto fez história nos anos 90. E ainda está aberta. O Estado de São Paulo, São Paulo, 7 ago. 2009. Disponível em: <http:// brasil.estadao.com.br/noticias/geral,boate-que-dara-lugar-ao-projeto-fez-historia-nos-anos-90-e-ainda-esta-aberta,414879>. Acesso em: 26 out. 2014. 
SÁNCHEZ, F; BIENENSTEIN, G. Jogos Pan-americanos Rio 2007: um balanço multidimensional. In: LATIN AMERICAN STUDIES ASSOCIATION (LASA), 28, 2009, Rio de Janeiro. Anais do XXVIII Congresso da LASA. Rio de Janeiro: LASA, 2009.

SEIXAS, J. Os megaeventos na cidade: imagem social, política econômica e governança urbana. E-metropolis, v. 1, n. 2, p. 4-9, set. 2010.

SETE escritórios do país e do mundo disputam direito de projetar o novo MIS. Extra Online, Rio de Janeiro, 7 ago. 2009. Disponível em: <http://extra.globo.com/noticias/rio/ sete-escritorios-de-arquitetura-do-pais-do-mundo-disputam-direito-de-projetar-novomis-313403.html >. Acesso em: 26 set. 2014.

SPOSITO, M. E. B. O centro e as formas de expressão da centralidade urbana. Revista de Geografia, Presidente Prudente, v. 10, p. 1-18, 1991.

UCHÔA, A. Museu da Imagem e do Som terá boate no lugar da Help. Portal G1, Rio de Janeiro, 19 jan. 2010. Disponível em: <http://g1.globo.com/Noticias/ Rio/0,,MUL1453733-5606,00-MUSEU+DA+IMAGEM+E+DO+SOM+TERA+BOATE+NO+LUGAR+DA+HELP.html>. Acesso em: 26 out. 2014.

VENCEDOR da segunda fase do projeto Porto Maravilha é anunciado: consórcio formado por Odebrecht, OAS e Carioca levou PPP de R\$ 7,3 bilhôes. Portal 2014, 27 out. 2010. Disponível em: <http://www.portal2014.org.br/noticias/5625/VENCEDOR+DA+SEGUNDA+FASE+DO+PROJETO+PORTO+MARAVILHA+E+ANUNCIADO. html>. Acesso em: 26 set. 2014.

A B S T R A C T : The theme of this work is based on the role of international sports mega-events in the production of Rio de Janeiro's urban space, marked by the production of the "Olympic City". Initiated on the occasion of the Pan-American Games in 2007 and currently underway to host the Olympic Games in 2016, this production uses imported patterns of urbanization and applies the "Barcelona model" of urban design, under the paradigm of urban entrepreneurship and strategic planning. In this sense, mega-events are used as urban strategies and present themselves relevants in the (re)structuring of the city of Rio de Janeiro.

K E Y W O R D S : international sports mega-events; urban entrepreneurship; strategic planning; urban geography; production of urban space; urban structure. 